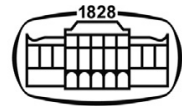

AKADÉMIAI KIADÓ

Journal of Behavioral

Addictions

10 (2021) 4, 920-931

DOI:

$10.1556 / 2006.2021 .00078$

(c) 2021 The Author(s)

\section{FULL-LENGTH REPORT}

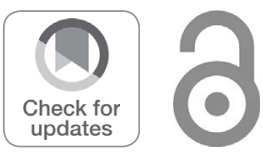

\title{
Skin gambling predicts problematic gambling amongst adolescents when controlling for monetary gambling
}

\author{
NERILEE HING ${ }^{1 *}$ (D) ALEX M. T. RUSSELL ${ }^{1}{ }^{\oplus}$, \\ GABRIELLE M. BRYDEN ${ }^{1}$ (๑), PHILIP NEWALL ${ }^{1}{ }^{\circ}$, \\ DANIEL L. KING ${ }^{2}$,, MATTHEW ROCKLOFF $^{1}$ (1), \\ MATTHEW BROWNE ${ }^{1}$ (D) and NANCY GREER ${ }^{1}$ (1) \\ ${ }^{1}$ Experimental Gambling Research Laboratory, School of Health, Medical and Applied Sciences, \\ CQUniversity, Australia \\ ${ }^{2}$ College of Education, Psychology, and Social Work, Flinders University, Australia
}

Received: July 21, 2021 • Revised manuscript received: September 18, 2021; October 13, 2021 • Accepted: 0ctober 18, 2021

Published online: November 15, 2021

\begin{abstract}
Background and aims: Skin gambling uses in-game items (skins) acquired in video games, to gamble on esports, games of chance, other competitive events and privately with friends. This study examined characteristics of adolescent skin gamblers, their engagement in monetary gambling, and relationships between skin gambling and at risk/problem gambling. Methods: Two samples of Australian adolescents aged 12-17 years were recruited to an online survey through advertisements $(n=843)$ and an online panel provider $(n=826)$. Results: In both samples, past-month skin gamblers ( $n=466$ advertisements sample; $n=185$ online panel sample) were more likely to have lower wellbeing, score as having an internet gaming disorder on the IGD, engage in more types of monetary gambling, and meet criteria for problem gambling on the DSM-IV-MR-J. Past-month skin gambling uniquely predicted problem gambling when controlling for past-month gambling on 11 monetary forms and the total number of monetary gambling forms. Discussion and conclusions: Underage participation in skin gambling is a growing concern. The strong convergence between engagement in skin gambling and monetary gambling suggests common risk factors may increase the propensity of some adolescents to gamble on these multiple forms. Nonetheless, past-month skin gambling predicted problem gambling even when controlling for past-month monetary gambling, indicating its unique contribution to gambling problems and harm. While the study was based on non-probability samples, its results strengthen the case for regulatory reforms, age restrictions and public health education to prevent underage skin gambling and its potentially harmful consequences for children and young people.
\end{abstract}

\section{KEYWORDS}

in-game items, skin betting, video games, loot boxes, gambling disorder, youth

\section{INTRODUCTION}

Playing video games is nearly ubiquitous amongst adolescents in many countries. In Australia, over $80 \%$ of children aged 5-17 years play video games for an average of $1-2 \mathrm{~h}$ each day (Brand, Jervis, Huggins, \& Wilson, 2020). Many video games enable players to acquire cosmetic items known as skins to enhance and customise their avatar, weapons or equipment, although many of these skins have no impact on game-play performance (Browne, 2020; McLeod, 2017; Parent Zone, 2018). Skins are most often obtained in video game loot boxes. Loot boxes are digital containers within many popular video games that can be purchased with real money or in-game currency, or awarded for free (Greer, Rockloff, 
Browne, Hing, \& King, 2019; Greer, Rockloff, \& Russell, 2021; King \& Delfabbro, 2018; Macey \& Hamari, 2019). When opened, loot boxes reveal randomised virtual rewards, such as weapons, special abilities and skins (Drummond \& Sauer, 2018; Drummond, Sauer, Hall, Zendle, \& Loudon, 2020; Greer et al., 2019; Zendle, Meyer, Cairns, Waters, \& Ballou, 2020). Gaining new, rare and valued skins is an important motivation for purchasing loot boxes since skins afford players prestige and social cachet (Hing et al., 2020; Parent Zone, 2019; Rockloff et al., 2020, 2021; Wardle, 2021).

Skins are one mechanism by which video games are monetised in otherwise free-to-play business models (Alha, Koskinen, Paavilainen, Hamari, \& Kinnunen, 2014; Hamari \& Lehdonvirta, 2010; Hamari et al., 2017; Lehdonvirta, 2009). Johnson and Brock (2020) argue that this trend to monetisation in digital games has been driven by the increased costs of developing and marketing "blockbuster" games, market saturation, and significant shifts in the corporate culture of the gaming industry where games are designed to maximise profit through continued innovation and gamblification of microtransactions in games. As noted by Wardle (2021), the digital games industry has spawned cultural and economic ecosystems designed to create need, create value, create habits and, importantly, create profit. Ingame purchasing and loot boxes top parental concerns about children's video gaming (Brand et al., 2020), and young people themselves recognise they are being coerced to spend money in games (Parent Zone, 2019; Wardle, 2021).

In addition to their social value, skins can have financial value, ranging from a few cents to many thousands of dollars, although not all skins can be traded (Thorhauge \& Neilson, 2021; Wardle, 2021). Skins with financial value can also be used to gamble via third-party websites on esports, games of chance and other competitive events (Greer et al., 2019; Wardle, 2021). These skin gambling websites are one of several nodes in the platform ecosystem of game distributors, where capital circulates as participants play the games and acquire in-game items that they can sell, trade or use to gamble on skin gambling websites (Zanescu, Lajeunesse, \& French, 2021). Skin gambling websites collaborate with the platform to access in-game items stored in digital inventory, allowing consumers to bet with these items instead of with money, although winnings can be paid as real money. This system enables the game distributor to avoid being classified and regulated as a gambling operator (Wardle, 2021; Zanescu et al., 2021). However, skin gambling itself can be considered gambling since it involves staking something of value on an event with an uncertain outcome for the chance to win something of value (King, 2018). The vast majority of countries, including Australia, do not licence any skin gambling operators (International Association of Gaming Regulators, 2020), with those that operate doing so illegally. However, these operators are difficult to monitor, as they can quickly appear and disappear before authorities can detect them (Parent Zone, 2018).

While skin gambling remains rare in games and is largely confined to "blockbuster" games, the size of the skin gambling market has fluctuated over time (Abarbanel \& Macey, 2019; Greer et al., 2019). Valve first released skins in 2013 which could be purchased, sold or traded in Valve's Steam Marketplace and gambled on third-party websites (Greer et al., 2019). By 2016, the skin gambling market was estimated at US\$4.8 million (Grove, 2016a). In mid-2016, facing public criticism and class-action lawsuits for complicity in illegal gambling operations and underage gambling, Valve issued cease-and-desist notices to skin gambling websites, heralding a "precipitous drop" in skin gambling to an estimated $\$ 830$ million in 2017 (Grove, 2016b). While numerous websites shut down, many subsequently re-emerged and continued to accept underage customers (Greer et al., 2019). In mid-2018, taking advantage of Valve's 7-day trading ban on CSGO skins designed to further deter skin gambling, skin exchange operator OPSkins introduced VGO skins, an alternative form of skins based on blockchain technology. This new form of currency based on non-fungible tokens was outside the control of game developers and is also accepted by skin gambling operators (Abarbanel \& Macey, 2019; Greer et al., 2019).

Because skin gambling lacks age verification, it is easily accessed by minors (Haskell, 2017; McLeod, 2017). Further, skin gambling lacks gambling harm minimisation features such as information on the odds of winning, player activity statements, limit-setting and time-out options (Hing et al., 2021; King \& Delfabbro, 2019a, 2019b; King et al., 2019), which may elevate the risk of harm and behavioural addiction. However, little is known about skin gambling amongst adolescents, including its potential links with monetary gambling and problem gambling. To help address this gap in knowledge, this study addressed the following objectives:

1. Examine demographic and psychological characteristics of past-month adolescent skin gamblers.

2. Examine past-month participation in monetary forms of gambling by past-month adolescent skin gamblers.

3. Assess whether problem gambling severity varies by pastmonth engagement in skin gambling.

4. Assess whether past-month skin gambling predicts problem gambling severity when controlling for engagement in monetary forms of gambling.

Addressing these objectives will extend our understanding of adolescent engagement in skin gambling. This knowledge can inform the targeting of protective measures for young people by identifying any distinctive characteristics of those who gamble using skins, including demographic and psychological factors. Identifying the degree of convergence of skin gambling and monetary gambling participation amongst adolescents can also inform public health measures that aim to reduce underage gambling. Understanding the relationship between skin gambling, monetary gambling and gambling problems amongst youth will highlight whether skin gambling contributes uniquely to gambling harm to guide efforts into protecting young people from gambling harm. Below, we review previous research on skin gambling amongst adolescents, highlighting what is known about its prevalence, participants, and links with 
gambling problems. We then explain the study's methods and present and discuss its results.

\section{Previous research on skin gambling amongst adolescents}

Most research on skin gambling amongst youth has been conducted in the United Kingdom (UK). A UK survey of a representative quota sample of 1,001 children aged 13-18 years (Parent Zone, 2018) found that $27 \%$ were familiar with the term "skin gambling" and 10\% reported gambling using skins at least once. Skin gambling was about five times higher amongst males. Sequential youth gambling studies for the UK Gambling Commission $(2017,2018,2019)$ have also examined skin gambling. In the 2017 study, 11\% of 2,881 adolescents aged 11-16 years, recruited from 115 educational institutions, reported having bet with skins, with most (59\%) doing so in the past month. Skin gambling was much higher amongst males (20\%) than females (3\%), and amongst older adolescents, past-week monetary gamblers, and those who had played online simulated gambling games. However, only $3 \%$ of adolescents in the 2018 study, and 6\% in 2019, reported skin gambling. In a Finnish study, Macey, Hamari, Sjöblom, and Törhönen (2021) found that 14\% of a sample of 255 computer art and gaming event attendees, of whom $27 \%$ were aged under 18 years, engaged in skin lotteries.

In the Australian state of New South Wales, one-in-seven adolescents (14.5\%) reported using skins for gambling in the past year $-7.9 \%$ to bet privately with friends, $6.2 \%$ on esports competitions, $5.8 \%$ on another site on games of chance or skill, and $4.8 \%$ on other competitive events excluding esports (Hing et al., 2020). These results show the diversity of skin gambling options for young people. Males (17.7\%) were more likely than females $(10.3 \%)$ to participate in skin gambling in the past year, but participation did not differ by age. Adolescents were 2.5 times more likely to bet on esports with skins than with cash $(1.4 \%)$. The study identified a young age of commencement, with about twofifths of skin gamblers reporting they commenced when aged 10-12 years and another two-fifths when aged 13-15 years. This sample $(N=551)$ was recruited through flyers for delivery to all in-scope households in the state, but its representativeness may have been compromised due to interruptions from COVID lockdowns, flyer delivery problems and a low response rate.

Scarcely any studies have examined links between skin gambling, other gambling, and gambling problems in adolescents. In a representative sample of 755 Danish adolescents aged 12-16 years (Kristiansen \& Severin, 2020), a cluster analysis identified a subgroup $(n=123)$ with relatively high involvement in simulated gambling, skin gambling, and loot box purchasing that was also more vulnerable to gambling problems. A more detailed analysis of skin gambling was based on the 2017 UK Gambling Commission study (Wardle, 2019). Thirty-nine per cent of pastmonth adolescent skin gamblers had also gambled on other activities. This convergence was significantly higher amongst adolescents who were male, older, felt they were performing less well at school, and had gambled online or on fruit/slot machines. Rates of at-risk/problem gambling were higher amongst skin gamblers, but this relationship was attenuated once the number of monetary gambling activities undertaken was also included. Wardle (2019) concluded that at-risk/ problem gambling amongst adolescent skin gamblers is likely related to their broader gambling activities rather than to their participation in skin gambling alone. In a sample of 582 esports spectators, of whom $27 \%$ were aged under 18 years (Macey \& Hamari, 2019), 51\% engaged in gambling during the previous 12 months. Amongst these gamblers, substantial proportions gambled with skins, including on skins lotteries $(13.8 \%)$, casino games $(6.8 \%)$, poker $(1.2 \%)$ and other card games $(1.2 \%)$. Over half of the sample $(50.3 \%)$ were low risk (27.8\%), moderate risk (18\%) or problem gamblers $(4.5 \%)$. Problematic gambling behaviour was highest amongst those who gambled using all three channels examined (offline, online, and video-game-related channels), indicating that gambling problems amongst skin gamblers may potentially be related to their monetary gambling activities. Researchers (Greer et al., 2019; Wardle, 2021) and public interest groups (Browne, 2020; Parent Zone, 2018) have highlighted underage gambling and gambling problems as particular concerns relating to skin gambling.

\section{METHODS}

\section{Participants}

A probability sample needed to obtain large representative sub-samples of key interest (skin gamblers, problem gamblers) would be unfeasible. We therefore recruited nonprobability samples from sources expected to include more involved gamblers. The main analyses tested relationships between variables, so representative samples were not necessarily required (Russell, Browne, Hing, Rockloff, \& Newall, 2021). However, to enhance confidence in generalisability, we recruited two samples through very different means to check if results were consistent between them. Inclusion criteria for both samples were adolescents aged 12-17 years, residing in NSW (the funding agency's jurisdiction), having parental permission to participate, and the participant's informed consent.

Advertisements sample. This sample was recruited through email and online advertising. We emailed our previous gambling research participants who had consented to receive invitations for future research and resided in NSW. The email requested they ask any adolescents in their household if they would like to complete the survey. We expected that this recruitment method would yield higher than average gambling rates, given that adolescent gambling and gambling problems are associated with parental gambling and problem gambling (Dowling, Jackson, Thomas, \& Frydenberg, 2010; Dowling, Shandley et al., 2017; McComb \& Sabiston, 2010). We also advertised the survey for two weeks 
on Facebook, Instagram and Twitter, and via the funding agency's online communications channels. Individuals targeted by social media advertising or on gambling-related mailing lists are likely to be more involved gamblers. Respondents could enter a prize draw for an AU\$100 gift voucher which could be redeemed from one of over 150 online stores. This incentive was approved by our institutional ethics review board. The survey ran for three weeks from late-April 2020. A total of 1,473 started the survey, with 51 excluded for being outside the target age range, nine did not consent to take part, and nine were outside of NSW. Of the remaining 1,404 respondents, 561 started but did not finish the survey. There were no obvious data quality issues, leaving 843 usable responses (completion rate 60.0\%).

Qualtrics sample. Samples recruited from online panels tend to contain much higher proportions of more involved and problematic gamblers (Russell et al., 2021). We therefore recruited through Qualtrics, an agency which sources respondents from multiple panels. To optimise data quality, Qualtrics de-duplicated responses across panels through checks of IP address, similar responses, and respondents recruited from more than one panel. Attention check questions were included in the survey programming. After data collection, tests were conducted for straightlining, speeding through the survey, inconsistent responses, and nonsense responses in open-ended questions, with exclusion decisions made by two researchers. One researcher also conducted independent data quality checks in addition to those conducted by Qualtrics. The survey ran for three weeks from mid-April 2020. The survey was started by 4,101 potential respondents. Of those, 2,364 were excluded because they did not gain parental consent, 119 did not consent themselves, 504 were outside the targeted age range, 16 did not live in NSW and 32 sped through the survey. A further 8 were excluded for failing an attention check. This left 1,058 respondents, of whom two were excluded for data quality reasons, and 230 started but did not complete the survey (completion rate $78.2 \%$ ), for a final total of 826 usable responses. Respondents were compensated by Qualtrics based on their usual points-accumulation system.

Qualtrics does not host their own panel, but instead recruits from other panels, meaning that any biases from a particular panel are reduced, and larger sample sizes are possible. While Qualtrics conducts the recruitment phase, in conjunction with the panel providers themselves, the research team is consulted extensively before, during and after recruitment. No decisions are made without consulting the research team. The researchers make the final decision about responses retained and those discarded based on quality issues. Discarded responses are replaced with data from newly recruited respondents at no additional cost to the researchers. Qualtrics often suggest potential deletions that on further inspection we opt to keep, indicating they prioritise the provision of high-quality data over profit maximisation. For a discussion of the potential strengths and weaknesses of paid online convenience samples, please see Russell et al. (2021).
To minimise any duplicate responses within and between samples, we cross-checked the email addresses and unique codes for follow-up provided by respondents. We also examined IP addresses. While adolescents from the same household could complete the survey, meaning that some IP duplication was possible, there was no wide scale duplication. Table 1 shows the main characteristics of respondents.

\section{Measures}

Skin gambling. Respondents were asked when they had last used in-game items for betting in the following ways: "Bet with in-game items on the outcome of a competitive video gaming contest (esports betting)"; "Bet on another site with in-game items ('skin betting') on a game of chance or skill (e.g., roulette, coin flip, jackpot)"; "Bet with in-game items on the outcome of other competitive events or sports (excluding esports)"; and "Used in-game items to bet privately with friends". Response options were "in the last 7 days", "in the last 4 weeks", "in the last 12 months", "more than 12 months ago" and "never'. A composite variable of past-month skin gambling was computed based on participation in any of these activities during the last 7 days or last 4 weeks.

Participation in monetary forms of gambling. Respondents were asked when they had last engaged in each of 11 gambling activities for money (see Table 3). Response options were the same as for the skin gambling items. A composite variable of past-month participation in each gambling activity was computed.

Problematic gambling. Problematic gambling was assessed using the DSM-IV-MR-J (Fisher, 2000), a widely used measure in Australian youth studies (King, Russell, \& Hing, 2020). The scale asks nine questions relating to the last 12 months (e.g., "How often have you found yourself thinking about gambling or planning to gamble?"). Respondents who endorsed 4 or more items were classified in the problem gambling category, $2-3$ items as at-risk, and $0-1$ items as non-problem gamblers. Cronbach's alpha (9 items) for this measure, combining both samples, was adequate at $0.79(n=989)$ and there was no improvement in alpha with the deletion of any item.

Psychological characteristics. Wellbeing was measured with the single item variable used to validate the Personal Wellbeing Index - School Children (Cummins \& Lau, 2005). Respondents rate how happy they are with their life as a whole $(0=$ very sad to $10=$ very happy).

Impulsiveness was measured with the Barratt Impulsiveness Scale - Brief (Steinberg, Sharp, Stanford, \& Tharp, 2013). The longer form of this scale has been validated amongst youth. The short form was used to reduce survey length. The BIS-Brief contains eight items (e.g., "I plan tasks carefully"). Appropriate items were reverse-coded, and items summed for a total score on a continuous scale. Cronbach's alpha (8 items) for this measure, combining both samples, was adequate at $0.71(n=1,669)$ and there was no improvement in alpha with the deletion of any item. 
Table 1. Key characteristics of respondents

\begin{tabular}{|c|c|c|c|c|}
\hline \multirow[b]{2}{*}{ Variables } & \multicolumn{2}{|c|}{ Advertisement Sample $(n=843)$} & \multicolumn{2}{|c|}{ Qualtrics Sample $(n=826)$} \\
\hline & $\mathrm{n}$ or $\mathrm{M}(\mathrm{SD})$ & $\%$ & $\mathrm{n}$ or $\mathrm{M}(\mathrm{SD})$ & $\%$ \\
\hline Age & $14.61(1.66)$ & - & $14.81(1.64)$ & - \\
\hline \multicolumn{5}{|l|}{ Gender } \\
\hline Female & 258 & 30.6 & 370 & 44.8 \\
\hline Male & 584 & 69.3 & 455 & 55.1 \\
\hline Other & 1 & 1 & 1 & 0.1 \\
\hline \multicolumn{5}{|l|}{ Indigenous } \\
\hline No, not Aboriginal or Torres Strait Islander & 440 & 52.2 & 742 & 89.8 \\
\hline Yes, Aboriginal & 171 & 20.3 & 40 & 4.8 \\
\hline Yes, Torres Strait Islander & 122 & 14.5 & 8 & 1.0 \\
\hline Yes, both Aboriginal and Torres Strait Islander & 94 & 11.2 & 4 & 0.5 \\
\hline Prefer not to say & 16 & 1.9 & 32 & 3.9 \\
\hline \multicolumn{5}{|l|}{ Paid Job } \\
\hline Yes & 118 & 14 & 246 & 29.8 \\
\hline No & 725 & 86 & 580 & 70.2 \\
\hline \multicolumn{5}{|l|}{ Parent's Living Arrangements } \\
\hline Living together & 534 & 63.3 & 637 & 77.1 \\
\hline Separated or divorced & 279 & 33.1 & 146 & 17.7 \\
\hline Have never lived together & 16 & 1.9 & 19 & 2.3 \\
\hline Something else & 14 & 1.7 & 24 & 2.9 \\
\hline Wellbeing & $7.22(2.95)$ & - & $8.73(1.92)$ & - \\
\hline Impulsiveness & $18.96(4.03)$ & - & $17.74(4.40)$ & - \\
\hline \multicolumn{5}{|l|}{ Problem Gambling } \\
\hline Non-gambler & 261 & 31.0 & 419 & 50.7 \\
\hline Non-problem-gambler & 92 & 10.9 & 203 & 24.6 \\
\hline At-risk gambler & 69 & 8.2 & 76 & 9.2 \\
\hline Problem gambler & 421 & 49.9 & 128 & 15.5 \\
\hline \multicolumn{5}{|l|}{ Past-month skin gambling on: } \\
\hline Esports & 216 & 25.6 & 116 & 14.0 \\
\hline Other competitive events & 226 & 26.8 & 93 & 11.2 \\
\hline Games of chance & 224 & 26.5 & 93 & 11.2 \\
\hline Privately with friends & 229 & 27.2 & 112 & 13.6 \\
\hline Any past-month skin gambling & 466 & 55.3 & 185 & 22.4 \\
\hline
\end{tabular}

Problematic gaming was measured with the Internet Gaming Disorder scale (Petry et al., 2014). It asks nine items relating to the last 12 months (e.g., "did you spend a lot of time thinking about games even when you were not playing, or planning when you could play next?"). Response options are no/yes. A score of 5 or more indicates problematic gaming, as long as one of the endorsed items is: "did you risk or lose significant relationships, or job, educational or career opportunities because of gaming?". Cronbach's alpha (9 items) for this measure, combining both samples, was adequate at $0.74(n=1,426)$ and there was no improvement in alpha with the deletion of any item.

Demographic characteristics. Included in the analysis were age, gender, indigenous status, whether they had a paid job, and their parents' living situation (see Table 1).

\section{Procedure}

Respondents were directed to an online information sheet which outlined the purpose of the study, inclusion criteria, how confidentiality would be protected, the voluntary nature of participation, and contact details for help services. If they passed the screening questions (12-17 years, NSW resident, parental permission, participant's consent), respondents could proceed to the online survey.

\section{Statistical analysis}

Analyses were conducted separately for the Advertisements and Qualtrics samples. To address objective 1, univariate binary logistic regressions were conducted to predict pastmonth skin gambling from each demographic and psychological variable. Assumptions for all logistic regressions were met, including independent observations, lack of multicollinearity (lowest tolerance $=0.448$ ) and the dependent variables being binary. No inflated error terms were observed. Demographic variables included age (continuous variable), gender (male, female; other was excluded from the analysis due to low numbers), indigenous status (Aboriginal and Torres Strait Islander vs non-indigenous; those who did not want to identify were excluded from the analysis), having a paid job (yes/no), and parent's living situation (living together vs other). Psychological variables included two continuous variables, wellbeing and impulsiveness, as well as internet gaming disorder (recoded to yes/no). To address objective 2, univariate binary logistic regressions were conducted to examine whether past-month participation in 
Table 2. Demographic and psychological variables predicting past-month skin gambling

\begin{tabular}{|c|c|c|c|c|c|c|c|c|c|c|}
\hline \multirow[b]{2}{*}{ Variables } & \multicolumn{5}{|c|}{$\begin{array}{c}\text { Advertisements Sample } \\
\text { Skin gambling vs not (ref = not) }\end{array}$} & \multicolumn{5}{|c|}{$\begin{array}{c}\text { Qualtrics Sample } \\
\text { Skin gambling vs not }(\text { ref }=\text { not })\end{array}$} \\
\hline & $B$ & S.E. & $\begin{array}{l}\text { Wald's } \\
\chi^{2}\end{array}$ & $P$ & $\begin{array}{l}\text { Odds } \\
\text { Ratio }\end{array}$ & $B$ & S.E. & $\begin{array}{l}\text { Wald's } \\
\chi^{2}\end{array}$ & $P$ & $\begin{array}{l}\text { Odds } \\
\text { Ratio }\end{array}$ \\
\hline Age (in years) & 0.047 & 0.042 & 1.259 & 0.262 & 1.048 & 0.176 & 0.053 & 10.855 & $0.001^{* *}$ & 1.192 \\
\hline Gender $(\text { ref }=\text { female })^{\wedge}$ & 0.262 & 0.152 & 2.992 & 0.084 & 0.769 & 0.861 & 0.180 & 22.889 & $<0.001^{* * *}$ & 2.366 \\
\hline $\begin{array}{l}\text { Indigenous } \\
\qquad(\text { ref }=\text { non-Indigenous })\end{array}$ & 1.980 & 0.161 & 151.349 & $<0.001^{* * * *}$ & 7.241 & 0.975 & 0.297 & 10.781 & $0.001^{* *}$ & 2.651 \\
\hline Paid Job $($ ref $=$ no $)$ & -1.022 & 0.209 & 23.996 & $<0.001^{* * *}$ & 0.360 & 1.050 & 0.173 & 36.651 & $<0.001^{* * *}$ & 2.858 \\
\hline $\begin{array}{l}\text { Parent's Living Arrangements } \\
\quad \text { (ref }=\text { not living together) }\end{array}$ & -0.947 & 0.151 & 39.350 & $<0.001^{* * *}$ & 0.388 & -0.147 & 0.272 & 0.291 & 0.589 & 1.144 \\
\hline Wellbeing & -0.274 & 0.028 & 92.502 & $<0.001^{* * *}$ & 0.761 & -0.088 & 0.042 & 4.452 & $0.035^{*}$ & 0.916 \\
\hline Impulsiveness & 0.139 & 0.019 & 53.290 & $<0.001^{* * *}$ & 1.149 & 0.032 & 0.019 & 2.905 & 0.088 & 1.033 \\
\hline $\begin{array}{l}\text { Internet Gaming Disorder } \\
\quad(\mathrm{ref}=\mathrm{no})\end{array}$ & 1.695 & 0.231 & 53.703 & $<0.001^{* * *}$ & 5.448 & 1.798 & 0.235 & 58.751 & $<0.001^{* * *}$ & 6.039 \\
\hline
\end{tabular}

${ }^{*} P<0.05 ;{ }^{* *} P<0.01 ; P<0.001$. Note: ${ }^{\wedge}$ Missing data for one person in each sample who indicated a gender other than male or female.

each of the 11 monetary gambling forms was related to pastmonth skin gambling. To address objective 3, binary logistic regressions were conducted to assess associations between past-month skin gambling as the outcome variable and the categories of non-gambler/non-problem gambler (NG/NPG), at-risk gambler (AR), and problem gambler (PG).

The fourth objective was first addressed with hierarchical binary logistic regressions, with step one (block 1) including past-month participation in the 11 monetary gambling forms, and step two (block 2) adding past-month skin gambling. Consistent with other youth gambling studies (e.g., Castrén, Grainger, Lahti, Alho, \& Salonen, 2015; Wardle, 2019), problem gambling severity was collapsed from four to two categories, as analyses using the initial categories were problematic because of small numbers in some cells. The two categories analysed were non-gambler/non-problem gambler (NG/NP) and at-risk/problem gambler (AR/PG). The fourth objective was further addressed with stepwise binary logistic regressions controlling for the total number of monetary forms of gambling. This was calculated by summing yes responses for past-month engagement in the individual forms. This total was entered into the first step of the regression, followed by past-month skin gambling in step two.

\section{Ethics}

The study procedures were carried out in accordance with the Declaration of Helsinki. The Institutional Review Board of the [Name of the Institute] approved the study. All subjects were informed about the study and all provided informed consent. Parental consent was sought for those younger than 18 years of age (all participants).

\section{RESULTS}

\section{Demographic and psychological characteristics of past-month adolescent skin gamblers}

In both samples, past-month skin gamblers were more likely to be indigenous, have lower wellbeing, and score as having an internet gaming disorder (Table 2). In the Advertisements sample, past-month skin gamblers were also more likely to have a paid job, have parents who did not live together and have higher impulsiveness scores. In the Qualtrics sample, past-month skin gamblers were also likely to be older and male but less likely to have a paid job.

\section{Past-month participation in monetary gambling by past-month adolescent skin gamblers}

Table 3 indicates a significant positive relationship between past-month skin gambling and past-month monetary gambling on each of the 11 forms, apart from keno in the Advertisements sample (note: horses/greyhound was not included due to one zero cell size). Past-month skin gamblers in both samples were more likely to engage in these types of monetary gambling in the last four weeks.

\section{Problem gambling severity by past-month skin gambling}

In both samples, problem gamblers were more likely to have participated in skin gambling in the last four weeks, compared with non-gamblers/non-problem-gamblers (Table 4). In the Qualtrics sample, at-risk gamblers were also more likely to have participated in skin gambling in the last four weeks, compared with non-gamblers/non-problem gamblers.

\section{Problem gambling severity by past-month skin gambling controlling for engagement in monetary gambling}

In both samples, past-month skin gambling significantly predicted at-risk/problem gambling, when controlling separately for past-month monetary gambling on each form (Table 5).

Consistent results were also found in both samples when controlling for the total number of monetary gambling forms. In the Advertisements sample, past-month skin 
Table 3. Past-month monetary gambling predicting past-month skin gambling

\begin{tabular}{|c|c|c|c|c|c|c|c|c|c|c|}
\hline \multirow[b]{2}{*}{ Variables $($ ref $=$ no $)$} & \multicolumn{5}{|c|}{$\begin{array}{c}\text { Advertisements Sample } \\
\text { Skin gambling vs not (ref = not) }\end{array}$} & \multicolumn{5}{|c|}{$\begin{array}{c}\text { Qualtrics Sample } \\
\text { Skin gambling vs not }(\text { ref }=\text { not })\end{array}$} \\
\hline & $B$ & $S E$ & Wald's $\chi^{2}$ & $P$ & Odds ratio & $B$ & $S E$ & Wald's $\chi^{2}$ & $P$ & Odds ratio \\
\hline Poker machines & 2.336 & 0.190 & 151.344 & $<0.001^{* * *}$ & 10.343 & 1.069 & 0.265 & 55.076 & $<0.001^{* * *}$ & 7.163 \\
\hline Horse or greyhound races ${ }^{1}$ & - & - & - & - & & 2.021 & 0.250 & 65.457 & $<0.001^{* * *}$ & 7.543 \\
\hline Scratchies, lottery, lotto, pools & 1.686 & 0.192 & 76.884 & $<0.001^{* * *}$ & 5.399 & 1.974 & 0.195 & 102.652 & $<0.001^{* * *}$ & 7.201 \\
\hline Keno & 0.835 & 0.526 & 2.522 & 0.112 & 2.304 & 2.201 & 0.293 & 56.223 & $<0.001^{* * *}$ & 9.031 \\
\hline Bingo or housie & 2.224 & 0.221 & 101.525 & $<0.001^{* * *}$ & 9.246 & 2.130 & 0.239 & 79.501 & $<0.001^{* * *}$ & 8.414 \\
\hline Poker & 2.019 & 0.749 & 7.276 & $0.007^{* *}$ & 7.533 & 2.204 & 0.324 & 46.196 & $<0.001^{* * *}$ & 9.061 \\
\hline Casino table games & 2.455 & 1.037 & 5.600 & $0.018^{*}$ & 11.646 & 3.171 & 0.452 & 49.222 & $<0.001^{* * *}$ & 23.830 \\
\hline Sporting events & 1.960 & 0.751 & 6.815 & $0.009^{* *}$ & 7.099 & 2.052 & 0.271 & 57.232 & $<0.001^{* * *}$ & 7.785 \\
\hline Esports & 2.399 & 0.197 & 148.985 & $<0.001^{* * *}$ & 11.010 & 2.438 & 0.262 & 86.578 & $<0.001^{* * *}$ & 11.448 \\
\hline Fantasy sports games & 2.726 & 0.205 & 176.516 & $<0.001^{* * *}$ & 15.278 & 2.279 & 0.280 & 66.468 & $<0.001^{* * *}$ & 9.770 \\
\hline Informal private betting & 2.346 & 0.180 & 169.511 & $<0.001^{* * *}$ & 10.445 & 1.793 & 0.210 & 72.619 & $<0.001^{* * *}$ & 6.009 \\
\hline
\end{tabular}

${ }^{*} P<0.05 ;{ }^{* *} P<0.01 ;{ }^{* * *} P<0.001$.

1. Sample size for horse or greyhound races was too small for this analysis.

Table 4. Past-month skin gambling predicting problem gambling (multinomial regression)

\begin{tabular}{|c|c|c|c|c|c|c|c|c|c|c|}
\hline \multirow[b]{2}{*}{ Variables } & \multicolumn{5}{|c|}{$\begin{array}{l}\text { Problem gambling (at-risk; ref }=\text { non-gamblers } \\
\text { and non-problem gamblers) }\end{array}$} & \multicolumn{5}{|c|}{$\begin{array}{l}\text { Problem gambling (problem; ref }=\text { non-gamblers } \\
\text { and non-problem gamblers) }\end{array}$} \\
\hline & $B$ & $S E$ & $\begin{array}{c}\text { Wald's } \\
\chi^{2}\end{array}$ & $P$ & $\begin{array}{l}\text { Odds } \\
\text { ratio }\end{array}$ & B & $S E$ & $\begin{array}{l}\text { Wald's } \\
\chi^{2}\end{array}$ & $P$ & $\begin{array}{l}\text { Odds } \\
\text { ratio }\end{array}$ \\
\hline $\begin{array}{l}\text { Skin gambling }(\mathrm{ref}=\text { not }) \\
\quad \text { (Advertisements sample) }\end{array}$ & 3.398 & 0.342 & 98.497 & 0.155 & 29.895 & 4.011 & 0.223 & 322.386 & $<0.001^{* * *}$ & 55.208 \\
\hline $\begin{array}{l}\text { Skin gambling }(\text { ref }=\text { not }) \\
\quad \text { (Qualtrics sample) }\end{array}$ & 2.241 & 0.268 & 69.777 & $<0.001^{* * *}$ & 9.404 & 3.194 & 0.239 & 177.915 & $<0.001^{* * * *}$ & 24.379 \\
\hline
\end{tabular}

${ }^{*} P<0.05 ;{ }^{* *} P<0.01 ;{ }^{* * *} P<0.001$.

1. Omnibus test of model: Advertisement sample (Likelihood Ratio $\chi^{2}=525.188$; $\mathrm{df}=2 ; P<0.001^{* * *}$ ); Qualtrics sample (Likelihood Ratio $\left.\chi^{2}=238.381 ; \mathrm{df}=2 ; P<0.001^{* * *}\right)$.

2. NG $=$ non-gamblers; $\mathrm{NPG}=$ non-problem-gamblers.

gamblers were significantly more likely to be at-risk or problem gamblers $\left(B=2.52, S E=0.41\right.$, Wald $\chi^{2}=38.31, d f$ $=1, P<0.001$, odds ratio $=12.464)$, after controlling for the total number of monetary gambling forms $(B=2.42, S E=$ 0.22 , Wald $\chi^{2}=125.77, d f=1, P<0.001$, odds ratio $=$ 11.215). Similarly, in the Qualtrics sample, past-month skin gamblers were significantly more likely to be at-risk or problem gamblers $\left(B=2.09, S E=0.07\right.$, Wald $\chi^{2}=83.18, d f$ $=1, P=0.001$, odds ratio $=8.086)$, after controlling for the total number of monetary gambling forms $(B=0.64, S E=$ 0.07 , Wald $\chi^{2}=75.59, d f=1, P<0.001$, odds ratio $=$ 1.896).

\section{DISCUSSION}

This study has contributed to the scant research into adolescent skin gamblers by examining their demographic and psychological characteristics, engagement in monetary gambling, and the relationship between skin gambling and gambling problems. Consistent with representative samples in the UK (Gambling Commission, 2017, 2019; Parent Zone, 2018), skin gamblers in the Qualtrics sample were more likely to be male, but no association was found in the Advertisements sample. Similarly, older age was associated with past-month skin gambling in the Qualtrics sample but not in the Advertisements sample. In adolescent gambling research, mixed results for age have been found, with some studies indicating that skin gamblers tend to be older (Gambling Commission, 2017; Parent Zone, 2018), while other studies find no association with age (Gambling Commission, 2019; Hing et al., 2020). More consistently, recent skin gamblers in both of our samples were more likely to identify as indigenous, report lower wellbeing and report internet gaming disorder symptoms. Our cross-sectional research cannot establish causal pathways, if any, between the psychological factors and skin gambling. Skin gambling may cause lower wellbeing, those with lower wellbeing may be particularly drawn to gambling with skins, or there may a third variable explanation for this relationship. Likewise, skin gambling may lead to an internet gaming disorder if adolescents spend excessive time playing digital games in order to acquire skins for gambling; or adolescents with an internet gaming disorder may be particularly attracted to skin gambling as a means to profit from the skins they acquire from digital games. Regardless of any causal direction, 
Table 5. Past-month monetary gambling by type and past-month skin gambling predicting problem gambling

\begin{tabular}{|c|c|c|c|c|c|c|c|c|c|c|}
\hline \multirow[b]{2}{*}{ Variables } & \multicolumn{5}{|c|}{$\begin{array}{c}\text { Advertisements Sample } \\
\text { Problem Gambling NG/NPG vs AR/PG } \\
\text { (ref = NG/NPG) }\end{array}$} & \multicolumn{5}{|c|}{$\begin{array}{c}\text { Qualtrics Sample } \\
\text { Problem Gambling NG/NP vs AR/PG } \\
\text { (ref = NG/NPG) }\end{array}$} \\
\hline & $B$ & $S E$ & $\begin{array}{c}\text { Wald's } \\
\chi^{2}\end{array}$ & $P$ & $\begin{array}{l}\text { Odds } \\
\text { ratio }\end{array}$ & $B$ & $S E$ & $\begin{array}{c}\text { Wald's } \\
\chi^{2}\end{array}$ & $P$ & $\begin{array}{l}\text { Odds } \\
\text { ratio }\end{array}$ \\
\hline \multicolumn{11}{|l|}{ Monetary gambling } \\
\hline Poker machines & 3.553 & 0.726 & 23.952 & $<0.001^{* * *}$ & 34.935 & 1.443 & 0.485 & 8.846 & $0.003^{* *}$ & 4.234 \\
\hline Horse/greyhound racing & -0.110 & 1.216 & 0.008 & 0.928 & 1.116 & 0.600 & 0.464 & 1.670 & 0.196 & 1.822 \\
\hline $\begin{array}{l}\text { Scratchies, lottery, lotto, } \\
\text { pools }\end{array}$ & 2.536 & 0.599 & 17.950 & $<0.001^{* * *}$ & 12.634 & 0.830 & 0.284 & 8.553 & $0.003^{* *}$ & 2.293 \\
\hline Keno & 2.740 & 1.358 & 4.072 & $0.044^{*}$ & 15.479 & 0.281 & 0.507 & 0.308 & 0.579 & 1.325 \\
\hline Bingo & 3.653 & 0.848 & 18.610 & $<0.001^{* * *}$ & 38.708 & 0.549 & 0.386 & 2.029 & 0.154 & 1.732 \\
\hline Poker & 0.870 & 1.606 & 0.294 & 0.588 & 2.114 & 1.717 & 0.681 & 6.361 & $0.012^{*}$ & 5.568 \\
\hline Casino table games ${ }^{3}$ & - & - & - & - & & -0.529 & 0.740 & 0.510 & 0.475 & 0.589 \\
\hline Sporting events & -1.208 & 1.043 & 1.341 & 0.247 & 0.299 & 0.663 & 0.480 & 1.913 & 0.167 & 1.942 \\
\hline Esports & 1.665 & 0.669 & 6.192 & $0.013^{*}$ & 5.285 & -0.188 & 0.433 & 0.189 & 0.664 & 0.829 \\
\hline Fantasy sports & 2.990 & 0.661 & 20.450 & $<0.001^{* * *}$ & 19.891 & 0.764 & 0.501 & 2.323 & 0.127 & 2.146 \\
\hline Informal private betting & 2.782 & 0.500 & 30.989 & $<0.001^{* * *}$ & 16.154 & 0.777 & 0.307 & 6.430 & $0.011^{*}$ & 2.175 \\
\hline Skin gambling & 2.730 & 0.476 & 32.84 & $<0.001^{* * *}$ & 15.333 & 2.202 & 0.237 & 86.218 & $<0.001^{* * *}$ & 9.047 \\
\hline Constant & -4.580 & 0.459 & 99.776 & $<0.001^{* * *}$ & 0.010 & -2.590 & 0.156 & 274.633 & $<0.001^{* * *}$ & 0.075 \\
\hline
\end{tabular}

${ }^{*} P<0.05 ;{ }^{* *} P<0.01 ;{ }^{* * *} P<0.001$.

1. Two problem gambling categories: NG/NPG $=$ Non-Gamblers plus Non-Problem-Gamblers; AR/PG $=$ At-risk gamblers plus $P G=$ Problem Gamblers.

2. Omnibus test of final model: advertisement sample (Block: Likelihood $\chi^{2}=37.049$; $\mathrm{df}=1 ; P<0.001^{* * *}$; Model: Likelihood Ratio $\chi^{2}=$ 987.395; $\mathrm{df}=11 ; P<0.001^{* * *}$ ); Qualtrics sample (Block: Likelihood $\chi^{2}=11.083$; $\mathrm{df}=1 ; P=0.001^{* *}$; Model: Likelihood Ratio $\chi^{2}=$ 288.518; $\left.\mathrm{df}=12 ; P=0.001^{* *}\right)$.

3. Sample size for the casino table games category was too small for this analysis.

these demographic and psychological characteristics suggest that measures to prevent underage skin gambling should be directed at all genders, adolescents of all ages, youth who are heavily engaged in digital gaming, and those at-risk of poorer health and wellbeing. The significant association of past-month skin gambling with indigenous status in both samples also suggests the importance of culturally-specific measures to dissuade underage skin gambling.

Consistent with Wardle's (2019) findings based on the 2017 UK youth gambling study (Gambling Commission, 2017), the current study found significant associations in both samples between recent participation in skin gambling and most types of monetary gambling. This convergence suggests a common set of risk factors may heighten the propensity of some adolescents to gamble on these multiple forms, including skin gambling. Previous research has implicated several psychological factors, including depression, anxiety and poor coping (Blinn-Pike, Worthy, \& Jonkman, 2010; Dussault, Brendgen, Vitaro, Wanner, \& Tremblay, 2011; Laconi, Vigouroux, Lafuente, \& Chabrol, 2017), which may be reflected in the lower wellbeing found in both our samples of recent skin gamblers. Risk-taking, sensation-seeking and impulsivity have also been implicated in youth gambling (Jackson, Dowling, Thomas, Bond, \& Patton, 2008; Reardon, Wang, Neighbors, \& Tackett, 2019; Walther, Morgenstern, \& Hanewinkel, 2012). Higher impulsiveness was associated with recent skin gambling in our study, but only in the Advertisements sample. Parental role modelling and monitoring (Dowling, Merkouris, et al.,
2017; Magoon \& Ingersoll, 2006; McComb \& Sabiston, 2010), peer group pressures and norms (Dowling, Merkouris, et al., 2017; Savolainen, Sirola, Kaakinen, \& Oksanen, 2019), environmental factors such as exposure to gambling advertising (Hing, Vitartas, Lamont, \& Fink, 2014; O'Brien \& Iqbal, 2019), and engagement in platform ecosystems that support the normalisation of gambling (Wardle, 2021; Zanescu et al., 2021) can also influence underage gambling. It is likely that certain psychosocial factors exert similar influences on youth engagement in skin gambling as they do for other forms of gambling. Future research could examine a broader set of risk factors for adolescent gambling, particularly modifiable parental, peer, gaming and marketing factors, to better understand influences that encourage underage gambling and how they might be modified.

Given the strong convergence between skin gambling and monetary gambling, it was not surprising that adolescents in the problem gambling category were more likely to have recently participated in skin gambling, compared to those without gambling problems. However, past-month skin gambling predicted at-risk/problem gambling even when controlling for past-month engagement in all monetary gambling forms, as well as the total number of forms. In contrast to Wardle's finding (2019) that the relationship between past-month skin gambling and at-risk/problem gambling was attenuated once the number of gambling activities undertaken was also included, recent skin gambling uniquely predicted gambling problems in both of our samples. This finding indicates that skin gambling is associated 
with gambling harm amongst young people, regardless of their engagement in monetary gambling activities, highlighting the importance of specific measures to reduce this type of underage gambling.

Like all research, this study has limitations. The two samples were self-selecting and not representative of the broader youth population. However, most analyses yielded consistent results for the two samples, which adds confidence that these effects were not artefacts of a particular recruitment method. Another limitation was the crosssectional design based on self-reported data, which are subject to recall and other biases. The survey wording referred to gambling with "in-game items". While skins are by far the most common type of in-game item to be gambled, some participants may have gambled with other in-game items such as audio clips, emotes, sprays, and ingame currency, and included these in their responses. Nonetheless, the inclusion of other types of in-game items in survey responses is likely to have little effect on the results, given the dominance of skins as gambling currency in this context. The surveys also coincided with the start of a national COVID-19 lockdown in Australia which may have affected some results, although skin gambling remained available online during the lockdown. Lastly, although we found a relationship between skin gambling frequency and problems whilst controlling for participation in other forms of gambling, for practical reasons it was not possible to gain an understanding of the spend on all activities. It is possible, although perhaps not probable, that adolescents who gamble using skins (vs those who do not) spend higher amounts on other forms of gambling, with the latter being the source of their gambling problems. Despite these limitations, this is one of the few studies to examine skin gambling amongst youth. It also recruited much larger samples of skin gamblers and problematic gamblers than have previously been obtained, which greatly increased the reliability of our estimates of associations with these variables.

\section{CONCLUSIONS}

This study examined characteristics of adolescent skin gamblers, their engagement in monetary gambling, and relationships between skin gambling and at risk/problem gambling. Two samples of Australians aged 12-17 years were recruited to an online survey through advertisements $(n=843)$ and an online panel provider $(n=826)$. In both samples, past-month skin gamblers were more likely to have lower wellbeing, report gaming disorder symptoms, and meet criteria for problem gambling, indicating that skin gambling is particularly attractive to youth with some apparent vulnerabilities. Past-month skin gambling also uniquely predicted problem gambling amongst adolescents independently of their gambling on 11 monetary forms. Being one of the few studies on the topic, these findings extend our understanding of adolescent engagement in skin gambling, and its potential contribution to gambling harm.
This is important, given that recent studies indicate that a substantial minority of adolescents engage in skin gambling, and this is likely to increase given the ubiquity of youth engagement in digital gaming, the popularity of skins, the normalisation of gambling, and the poor regulation of skin gambling websites. Population studies are needed with sufficient sub-samples of problematic gamblers and skin gamblers to confirm if the current findings remain consistent in a representative sample. Prospective and experimental studies could valuably examine causal relationships between skin gambling, monetary gambling, and problem gambling amongst adolescents.

The robust association between skin gambling and gambling problems strengthens the case for better monitoring and regulation of skin gambling. Skin gambling is clearly contributing to underage gambling, facilitated by ease of access and lack of age restrictions. To prevent underage access, skin gambling operators should be required to have a gambling licence and to impose age restrictions with rigorous age verification processes and enforced with meaningful penalties for non-compliance. Public health measures are also needed to raise awareness amongst parents and young people about the risks of skin gambling and its illegality (in jurisdictions where it is illegal), along with parental education about how they can deter their children from gambling with skins, for example through advice, monitoring and website blocking. Given the contribution of skin gambling to gambling problems, regulators should also require skin gambling operators to implement harm minimisation and consumer protection features. At minimum, these should align with requirements for other forms of online gambling. In Australia, these include the ability to set limits on betting, self-exclude, access player activity statements, opt out of receiving gambling inducements, and access information about gambling odds, gambling harm and help services (Department of Social Services, 2018). Additional restrictions could also be placed on game operators, for example age-gating video games with loot boxes containing skins, especially given that loot boxes themselves are properly considered a form of gambling (Rockloff et al., 2020, 2021). Researchers have also advocated for closer scrutiny of the increasing entanglement of gambling with game monetisation, the potential exploitative or coercive nature of gamblified games, and the monopolistic platforms that integrate game play and market transactions with ingame rewards that can also be gambled on third-party websites (Johnson \& Brock, 2020; Wardle, 2021; Zanescu et al., 2021). Whitson and French (2021) and Wardle (2021) note that the fuzzy line between gambling and gaming complicates the regulation of digital games and enables game operators to escape the regulatory oversight afforded to gambling. Similar to arguments made in relation to responsible provision and consumption of gambling (e.g., Hancock \& Smith, 2017; Livingstone \& Rintoul, 2020; Schüll, 2012), they call for greater emphasis on consumer protection through the responsible production of digital games rather than a reliance on responsible consumption. 
More broadly, the findings of this study highlight the potential harms to young people from the increasing intersection of gaming and gambling. While the study focused on individual factors associated with adolescent skin gambling, this engagement occurs within the wider ecosystem of digital games which have become increasingly monetised to maximise corporate profits through systems aimed at optimising and locking in consumers' participation on the platform (Wardle, 2021; Whitson \& French, 2021; Zanescu et al., 2021). Continued research is needed into the increasing gamblification of digital games that prioritises profits over consumer protection, its effects on consumers, and how to protect children and young people from the associated harms.

Funding sources: Funding for this study was provided by the NSW Government's Responsible Gambling Fund, with support from the NSW Office of Responsible Gambling.

Authors' contribution: NH, AR, MR, MB, PN, NG and DK designed the study and the survey instrument. GB conducted the statistical analyses and compiled the results tables. $\mathrm{NH}$ completed the first draft of the manuscript. All authors refined and approved the submitted version of the manuscript.

Conflicts of interest: The authors declare no conflicts of interest in relation to this manuscript.

\section{REFERENCES}

Abarbanel, B., \& Macey, J. (2019). VGO, NFT, OMG! Commentary on continued developments in skins wagering. Gaming Law Review, 23(1), 23-25. https://doi.org/10.1089/glr2.2019.2312.

Alha, K., Koskinen, E., Paavilainen, J., Hamari, J., \& Kinnunen, J. (2014). Free-to-Play games: Professionals' perspective. Proceedings of DiGRA Nordic 2014. Retrieved from http://www. digra.org/digital-library/publications/free-to-play-gamesprofessionals-perspectives/.

Blinn-Pike, L., Worthy, S. L., \& Jonkman, J. N. (2010). Adolescent gambling: A review of an emerging field of research. Journal of Adolescent Health, 47, 223-236. https://doi.org/10.1016/j. jadohealth.2010.05.003.

Brand, J. E., Jervis, J., Huggins, P. M., \& Wilson, T. W. (2020). Digital Australia 2020. Everleigh: Interactive Games and Entertainment Association.

Browne, B. (2020). Gambling on games: How video games expose children to gambling. Discussion paper. Canberra: Australia Institute.

Castrén, S., Grainger, M., Lahti, T., Alho, H., \& Salonen, A. H. (2015). At-risk and problem gambling among adolescents: A convenience sample of first-year junior high school students in Finland. Substance Abuse Treatment, Prevention, and Policy, 10(1), 1-10. https://doi.org/10.1186/s13011-015-0003-8.

Cummins, R. A., \& Lau, A. L. (2005). Personal wellbeing index School children. Melbourne: School of Psychology, Deakin University.
Department of Social Services (DSS). (2018). National consumer protection framework for online wagering in Australia - National policy statement. Retrieved from https://www.dss.gov.au/sites/ default/files/documents/11_2018/national-policy-statement.pdf.

Dowling, N., Jackson, A. C., Thomas, S. A., \& Frydenberg, E. (2010). Children at risk of developing problem gambling. Melbourne: Gambling Research Australia.

Dowling, N. A., Merkouris, S. S., Greenwood, C. J., Oldenhof, E., Toumbourou, J. W., \& Youssef, G. J. (2017). Early risk and protective factors for problem gambling: A systematic review and meta-analysis of longitudinal studies. Clinical Psychology Review, 51, 109-124. http://doi.org/10.1016/j.cpr.2016.10.008.

Dowling, N. A., Shandley, K. A., Oldenhof, E., Affleck, J. M., Youssef, G. J., Frydenberg, E., .. Jackson, A. C. (2017). The intergenerational transmission of at-risk/problem gambling: The moderating role of parenting practices. The American Journal on Addictions, 26(7), 707-712. https://doi.org/10.1111/ajad.12599.

Drummond, A., \& Sauer, J. D. (2018). Video game loot boxes are psychologically akin to gambling. Nature Human Behaviour, 2(8), 530-532. https://doi.org/10.1038/s41562-018-0360-1.

Drummond, A., Sauer, J. D., Hall, L. C., Zendle, D., \& Loudon, M. R. (2020). Why loot boxes could be regulated as gambling. Nature Human Behaviour, 4(10), 986-988. https://doi.org/10. 1038/s41562-020-0900-3.

Dussault, F., Brendgen, M., Vitaro, F., Wanner, B., \& Tremblay, R. E. (2011). Longitudinal links between impulsivity, gambling problems and depressive symptoms: A transactional model from adolescence to early adulthood. Journal of Child Psychology and Psychiatry, 52(2), 130-138. https://doi.org/10.1111/ j.1469-7610.2010.02313.x.

Fisher, S. E. (2000). Developing the DSM-IV-MR-J criteria to identify adolescent problem gambling in non-clinical populations. Journal of Gambling Studies, 16, 253-273. https://doi. org/10.1023/A:1009437115789.

Gambling Commission. (2017). Young people and gambling 2017: A research study among 11-16 year olds in Great Britain. Gambling Commission.

Gambling Commission. (2018). Young people and gambling 2018: A research study among 11-16 year olds in Great Britain. London: UK Gambling Commission.

Gambling Commission. (2019). Young people and gambling survey 2019: A research study among 11-16 year olds in Great Britain. London: Great Britain.

Greer, N., Rockloff, M., Browne, M., Hing, N., \& King, D. L. (2019). Esports betting and skin gambling: A brief history. Journal of Gambling Issues, 43. http://igi.camh.net/doi/pdf/10.4309/jgi. 2019.43.8.

Greer, N., Rockloff, M., \& Russell, A. M. T. (2021). Gambling and video games: Are esports betting and skin gambling associated with greater gambling involvement and harm? Melbourne: Victorian Responsible Gambling Foundation.

Grove, C. (2016a). Understanding skin gambling. Retrieved from https://www.thelines.com/wp-content/uploads/2018/03/SkinGambling-White-Paper-V2.pdf.

Grove, C. (2016b). Esports and gambling: Where's the action? Narus and Eilers \& Krejcik Gaming. Retrieved from https:// www.thelines.com/wp-content/uploads/2018/03/Esports-andGambling.pdf. 
Hamari, J., Alha, K., Järvelä, S., Kivikangas, J. M., Koivisto, J., \& Paavilainen, J. (2017). Why do players buy in-game content? An empirical study on concrete purchase motivations. Computers in Human Behavior, 68, 538-546. https://doi.org/10. 1016/j.chb.2016.11.045.

Hamari, J., \& Lehdonvirta, V. (2010). Game design as marketing: How game mechanics create demand for virtual goods. International Journal of Business Science \& Applied Management, 5(1), 14-29. http://ssrn.com/abstract=1443907.

Hancock, L., \& Smith, G. (2017). Critiquing the Reno Model I-IV international influence on regulators and governments (20042015) - the distorted reality of "responsible gambling". International Journal of Mental Health and Addiction, 15(6), 11511176. https://doi.org/10.1007/s11469-017-9746-y.

Haskell, J. V. (2017). More than just skin(s) in the game: How one digital video game item is being used for unregulated gambling purposes online. Journal of High Technology Law, 18, 125. https://heinonline.org/HOL/P?h=hein.journals/jhtl18\&i=126.

Hing, N., Russell, A. M. T., Browne, M., Rockloff, M., Greer, N., Rawat, V., ... Woo, L. (2021). The second national study of interactive gambling in Australia (2019-20). Sydney: Gambling Research Australia.

Hing, N., Russell, A. M. T., King, D., Rockloff, M., Browne, M., Greer, N., ... Coughlin, S. (2020). NSW youth gambling study 2020. Sydney: NSW Responsible Gambling Fund.

Hing, N., Vitartas, P., Lamont, M., \& Fink, E. (2014). Adolescent exposure to gambling promotions during televised sport: An exploratory study of links with gambling intentions. International Gambling Studies, 14(3), 374-393. https://doi.org/10. 1080/14459795.2014.902489.

International Association of Gaming Regulators. (2020). Mini survey: Gaming and gambling - Blurred lines. Retrieved from https://www.iagr.org/sites/default/files/2864\%20IAGR\%20Mini \%20survey\%20report_Gambling\%20vs\%20gaming_May20.pdf.

Jackson, A. C., Dowling, N., Thomas, S. A., Bond, L., \& Patton, G. (2008). Adolescent gambling behaviour and attitudes: A prevalence study and correlates in an Australian population. International Journal of Mental Health and Addiction, 6(3), 325352. https://doi.org/10.1007/s11469-008-9149-1.

Johnson, M. R., \& Brock, T. (2020). The 'gambling turn' in digital game monetization. Journal of Gaming \& Virtual Worlds, 12(2), 145-163. https://doi.org/10.1177\%2F1469540521993904.

King, D. (2018). Online gaming and gambling in children and adolescents - Normalising gambling in cyber places. Melbourne, Australia: Victorian Responsible Gambling Foundation.

King, D. L. \& Delfabbro, P. H. (2018). Predatory monetization features in video games (e.g., 'loot boxes') and Internet gaming disorder. Addiction, 113, 1967-1969. https://doi.org/10.1111/add.14286.

King, D. L. \& Delfabbro, P. H. (2019a). Video game monetization (e.g., 'loot boxes'): A blueprint for practical social responsibility measures. International Journal of Mental Health and Addiction, 17, 166-179. https://doi.org/10.1007/s11469-018-0009-3.

King, D. L. \& Delfabbro, P. H. (2019b). Loot box limit-setting is not sufficient on its own to prevent players from overspending: A reply to Drummond, Sauer, and Hall. Addiction, 114, 13241325. https://doi.org/10.1111/add.14628.

King, D. L., Delfabbro, P. H., Gainsbury, S. M., Dreier, M., Greer, N., \& Billieux, J. (2019). Unfair play? Video games as exploitative monetized services: An examination of game patents from a consumer protection perspective. Computers in Human Behavior, 101, 131-143. https://doi.org/10.1016/j.chb. 2019.07.017.

King, D. L., Russell, A. M. T., \& Hing, N. (2020). Adolescent landbased and Internet-based gambling: Australian and international prevalence rates and measurement issues. Current Addiction Reports, 7, 137-148. https://rdcu.be/b3Dh0.

Kristiansen, S., \& Severin, M. C. (2020). Exploring groups of simulated gambling behaviour: A typological study among Danish adolescents. International Gambling Studies, 20(1), 135-150. https://doi.org/10.1080/14459795.2019.1697344.

Laconi, S., Vigouroux, M., Lafuente, C., \& Chabrol, H. (2017). Problematic internet use, psychopathology, personality, defense and coping. Computers in Human Behavior, 73, 47-54. https:// doi.org/10.1016/j.chb.2017.03.025.

Lehdonvirta, V. (2009). Virtual item sales as a revenue model: Identifying attributes that drive purchase decisions. Electronic Commerce Research, 9(1), 97-113.

Livingstone, C., \& Rintoul, A. (2020). Moving on from responsible gambling: A new discourse is needed to prevent and minimise harm from gambling. Public Health, 184, 107-112. https://doi. org/10.1016/j.puhe.2020.03.018.

Macey, J., \& Hamari, J. (2019). eSports, skins and loot boxes: Participants, practices and problematic behaviour associated with emergent forms of gambling. New Media \& Society, 21, 20-41. https://doi.org/10.1177/1461444818786216.

Macey, J., Hamari, J., Sjöblom, M., \& Törhönen, M. (2021). Relationships between the consumption of gamblified media and associated gambling activities in a sample of esports fans. Retrieved from https://trepo.tuni.fi/bitstream/handle/10024/ 133709/Relationships_between_the_consumption_of_ gamblified_.pdf? sequence $=1$ \&isAllowed $=\mathrm{y}$.

Magoon, M. E., \& Ingersoll, G. M. (2006). Parental modeling, attachment, and supervision as moderators of adolescent gambling. Journal of Gambling Studies, 22(1), 1-22. https://doi. org/10.1007/s10899-005-9000-6.

McComb, J. L. \& Sabiston, C. M. (2010). Family influences on adolescent gambling behavior: A review of the literature. Journal of Gambling Studies, 26, 503-520. https://doi.org/10. 1007/s10899-010-9181-5.

McLeod, C. (2017). More than skin deep: Why it's time to go 'all-in' on skin gambling regulation. Retrieved from https://papers.ssrn. com/sol3/papers.cfm?abstract_id=3159661.

O'Brien, K., \& Iqbal, M. (2019). Extent of, and children and young people's exposure to, gambling advertising in sport and nonsport TV. Melbourne: Victorian Responsible Gambling Foundation.

Parent Zone. (2018). Skin gambling: Teenage Britain's secret habit. Retrieved from https://parentzone.org.uk/system/files/ attachments/Skin_Gambling_Report_June_2018.pdf.

Parent Zone. (2019). The rip-off games: How the new business model of online gaming exploits children. Retrieved from https:// parentzone.org.uk/system/files/attachments/The\%20Ripoff\% 20Games\%20-\%20Parent\%20Zone\%20report.pdf.

Petry, N. M., Rehbein, F., Gentile, D. A., Lemmens, J. S., Rumpf, H.J., Mößle, T., ... O’Brien, C. P. (2014). An international consensus for assessing internet gaming disorder using the new 
DSM-5 approach. Addiction, 109(9), 1399-1406. https://doi. org/10.1111/add.12457.

Reardon, K. W., Wang, M., Neighbors, C., \& Tackett, J. L. (2019). The personality context of adolescent gambling: Better explained by the Big Five or sensation-seeking? Journal of Psychopathology and Behavioral Assessment, 41, 69-80. https:// doi.org/10.1007/s10862-018-9690-6.

Rockloff, M., Russell, A. M. T., Greer, N., Lolé, L., Hing, N., \& Browne. M. (2020). Loot boxes: Are they grooming youth for gambling? Sydney: NSW Responsible Gambling Fund. https:// doi.org/10.1556/2006.2021.00007.

Rockloff, M., Russell, A. M., Greer, N., Lole, L., Hing, N., \& Browne, M. (2021). Young people who purchase loot boxes are more likely to have gambling problems: An online survey of adolescents and young adults living in NSW Australia. Journal of Behavioral Addictions, 10(1), 35-41.

Russell, A. M. T., Browne, M., Hing, N., Rockloff, M., \& Newall, P. (2021). Are any samples representative or unbiased? Reply to Pickering and Blaszczynski. International Gambling Studies, published online 3 Sept 2021. https://doi.org/10.1080/14459795. 2021.1973535.

Savolainen, I., Sirola, A., Kaakinen, M., \& Oksanen, A. (2019). Peer group identification as determinant of youth behavior and the role of perceived social support in problem gambling. Journal of Gambling Studies, 35, 15-30. https://doi.org/10.1007/s10899018-9813-8.

Schüll, N. D. (2012). Addiction by design. Princeton University Press.

Steinberg, L., Sharp, C., Stanford, M. S., \& Tharp, A. T. (2013). New tricks for an old measure: The development of the Barratt impulsiveness scale-brief (BIS-brief). Psychological Assessment, 25(1), 216. https://psycnet.apa.org/doi/10.1037/a0030550.

Thorhauge, A. M., \& Nielsen, R. K. (2021). Epic, Steam, and the role of skin-betting in game (platform) economies. Journal of Consumer Culture, 21(1), 52-67. http://doi.org/10.1177/ 1469540521993929.

Walther, B., Morgenstern, M., \& Hanewinkel, R. (2012). Cooccurrence of addictive behaviours: Personality factors related to substance use, gambling and computer gaming. European Addiction Research, 18(4), 167-174. https://www.jstor.org/ stable/26790612.

Wardle, H. (2019). The same or different? Convergence of skin gambling and other gambling among children. Journal of Gambling Studies, 35(4), 1109-1125. https://doi.org/10.1007/ s10899-019-09840-5.

Wardle, H. (2021). Games without frontiers? Socio-historical perspectives at the gaming/gambling intersection. Retrieved from https://link.springer.com/content/pdf/10.1007\%2F978-3-03074910-1.pdf.

Whitson, J., \& French, M. (2021). Productive play: The shift from responsible consumption to responsible production. Journal of Consumer Culture, 21(1), 14-33. https://doi.org/10.1177\% 2F1469540521993922.

Zanescu, A., Lajeunesse, M., \& French, M. (2021). Speculating on steam: Consumption in the gamblified platform ecosystem. Journal of Consumer Culture, 1469540521993928.

Zendle, D., Meyer, R., Cairns, P., Waters, S., \& Ballou, N. (2020). The prevalence of loot boxes in mobile and desktop games. Addiction, 115(9), 1768-1772. https://doi.org/10.1111/add. 14973. 